\title{
Nurse's Awareness on Ethico-legal Aspects of Nursing Profession
}

\author{
Krishna Kumari Paudel Subedi, ${ }^{1}$ Kalpana Timalsina, ${ }^{1}$ Raja Laxmi Bhele ${ }^{1}$ \\ ${ }^{1}$ Nursing Department, Shahid Gangalal National Heart Centre Bansbari, Kathmandu, Nepal.
}

\section{ABSTRACT}

Background: Nursing practice amicably includes practical efficacy and ethics. Now a days legal and ethical problems associated with client care are arising day by day. Therefore, nurses should have adequate understanding of basic legal concepts and issues relevant to nursing profession in order to protect the rights of the clients and the nurses.

Methods: A cross sectional descriptive design was adopted for the study. 142 nurses were included by using purposive sampling technique. Data was collected with self-administered structured questionnaire. Descriptive statistics was used to reveal demographic information. Kruskal Wallis and Mann Whitney test were used to find out association of selected demographic variables and ethico legal aspects of nursing

Results: Majority of participants were belonging to 20-29 years of age. More than half nurses had complete bachelor's degree and had less than 10 year's experiences. Majority of participants reported that they did not encounter any legal issues in their professional life till date. Similarly, majority of participants had average level knowledge and equate level of practice. Years of experiences and education level did not affect in knowledge level and existing practice related to ethico legal aspect of nursing. There was no significant relationship between level of knowledge and existing practice. Conclusions: Nurses have average knowledge and practice on ethico legal aspects. There is positive relationship between knowledge and practice though it is not statistically significant.

Keywords: Ethico- legal; knowledge, nursing practice.

\section{INTRODUCTION}

Ethics is a branch of moral philosophy related to concepts of right and wrong. Ethics is especially essential for nurse to deal with the most fundamental human actions like birth, death pain grief etc. ${ }^{1}$ It is well known that laws, by nature, are dynamic. ${ }^{2}$ They relentlessly change in the wake of changes in society, delivery of health care and progress in medical technology. ${ }^{3}$ Nurses must know their legal obligation as they have to update with the fast changing and advancing professional knowledge to provide safe nursing to their clients on the basis of their necessities. ${ }^{2}$ Nurses are in doubt about the 'right' way to behave if they do not have in-depth understanding of law and ethics pertaining to nursing profession. ${ }^{4}$ All above mentioned reasons suggest that now it is time to assess awareness of nurses so that institute can include additional strategies to overhaul deficit areas if any.

\section{METHODS}

The study was a quantitative, cross sectional descriptive type, carried out from $27^{\text {th }}$ June to 16 October, 2016. This study was conducted in Shahid Gangalal National Heart Center, a tertiary level government Heart Institution where 220 nurses were working in various units during the time of study. Sample size was calculated by using Cochran formula $n_{0}=\left(Z^{2}{ }_{*} P(1-P) / d^{2}\right)$ for finite population. ${ }^{5}$ The required sample size of the study was 140 at $95 \%$ confidence level and $0.05 \%$ allowable error. Self-constructed questionnaire was used. Questionnaire consisted of three parts; Demographic information, information regarding knowledge on ethico-legal issues and information regarding existing practice on ethicolegal issues.

Researchers visited every nurse individually, then stated the objective of the study. By using purposive sampling technique, self-constructed questionnaires were disseminated to the 160 nurse participants who wished to take part in this study. Written consent was taken from every nurse participant before starting to fill the questionnaire. Finally, only 142 nurses returned back the questionnaires after they completed. Thus, rate of return was $88.77 \%$. After data collection questionnaire 
of each participants was coded and made ready for entry in to SPSS 16.

After completing of data entry, analysis was preceded. As per study purpose, descriptive statistic was used to reveal the demographic information. Knowledge related to legal aspect of nursing had shown in three level poor knowledge, average knowledge and adequate knowledge. Level of knowledge were categorized as poor who got below 50 score, and it was leveled as moderate who got 50 to below $75 \%$ and it was indicated as adequate who obtained the score above $75 \%$. This was based on Shrestha et $\mathrm{al}^{6}$ and Assefa et al. ${ }^{7}$ Level of existing practice was shown in two level; average level and adequate level. Practice was based on mean. Total score was 3 . Mean up to 2 is ranked as poor practice and mean above 2 to 3 is indicated as adequate practice. This category is also based on Shrestha et $\mathrm{al}^{6}$ and Assefa et al. ${ }^{7}$ Inferential statistics; Mann Whitney test, Kruskal Wallis tests and Spearman correlation coefficient test were used to examine nurse's knowledge and practice and the designated background variables of the participants. Finally, findings of the study were connected with the research questions and objectives. Similarly, findings of the study were also compared and differentiated with other related types of study conducted in other settings; nationally as well as globally.

Validity was maintained by doing far-reaching literature analysis and consulting with nurse professionals, other health experts and coworkers. Furthermore, for evaluating instrument's validity, three specialist nurses and one lawyer were requested for their judgment. Reliability of instrument was maintained by pretesting of the instrument among ten percent of total participants. As per suggestion some items were deleted and some were modified in order to make clear. Participants who were included in the pretest excluded from the large scale study.

Likewise, researchers consciously pursued the ethicalmoral issues for this study. Initially, approval was obtained from Institutional Research Committee (IRC) of this Centre. Likewise, the researchers approached to individual nurse participants working in the various units of this hospital and written assent was taken from them. The participants were guaranteed privacy of their valuable information; they were assured that they could withdraw their involvement from the research study whenever they like.

\section{RESULTS}

Table 1 depicts that majority of participants (69.7\%) had average level of knowledge, 19\% had adequate knowledge and only $11.3 \%$ had poor knowledge. Similarly, as per table 2, majority of participants (65.5\%) had adequate level of practice, $34.5 \%$ had average level of practice and none of the participants had insufficient level of practice regarding ethico- legal issues of nursing profession. Table 1 and 2 reflect that ethico-legal nurses of Shahid Gangalal National Heart Center had satisfactory level of knowledge and practice pertaining ethico-legal aspects.

\begin{tabular}{llrr}
$\begin{array}{l}\text { Table 1. Extent or Level of Knowledge of Participants on ethico-legal aspects of nursing profession } \\
\text { profession. }\end{array}$ & Extent or level of knowledge & Frequency & Percent \\
\hline Obtained sum score & Poor & 16 & 11.3 \\
\hline Up to 7 & Average & 99 & 69.7 \\
\hline $8.00-15$ & Adequate & 27 & 19.0 \\
\hline 16 and above & & 27 & 99 \\
\hline
\end{tabular}

Table 2. Extent of existing practicing culture of ethico-legal issues of nursing profession.

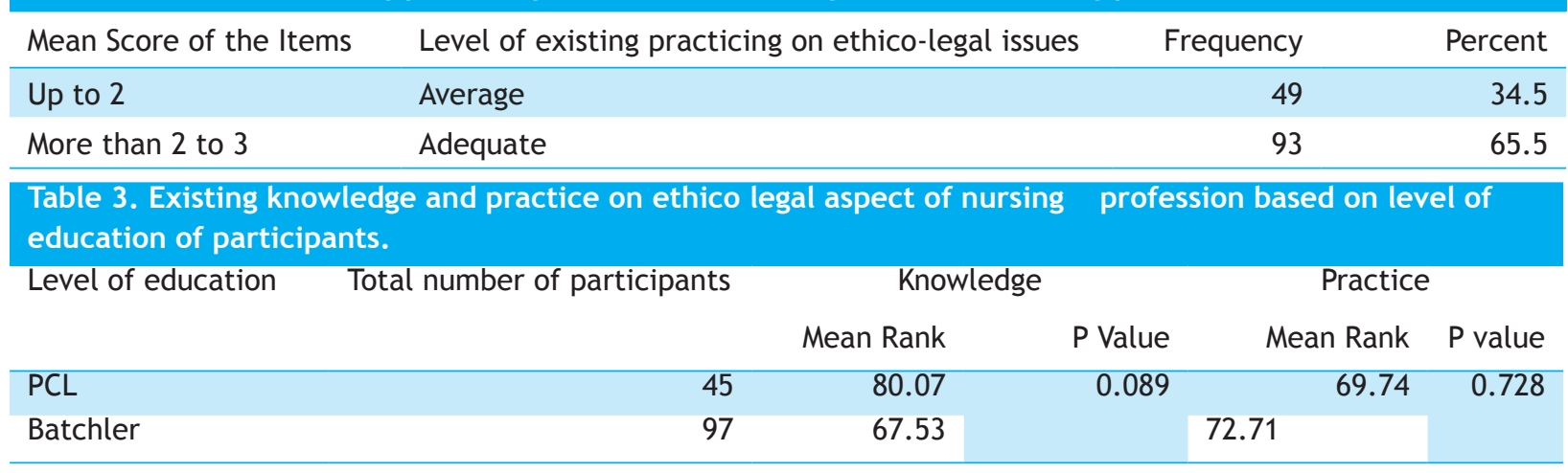


Nurse's Awareness on Ethico-legal Aspects of Nursing Profession

\begin{tabular}{|c|c|c|c|c|c|}
\hline \multirow[t]{2}{*}{ Years of experiences } & \multirow{2}{*}{ 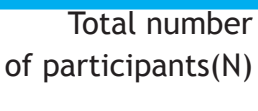 } & \multicolumn{2}{|c|}{ Knowledge } & \multicolumn{2}{|c|}{ Practice } \\
\hline & & Mean Rank & $P$ value & Mean rank & $P$ value \\
\hline Below 1 years & 12 & 72.00 & 0.165 & 56.21 & 0.316 \\
\hline $1-5$ & 76 & 73.76 & & 71.51 & \\
\hline $6-10$ & 42 & 61.89 & & 78.52 & \\
\hline
\end{tabular}

Table 5: Association between knowledge and practice on ethico-legal issues

\begin{tabular}{lrrrrr} 
Variables & Mean & SD & Spearman-Correlation coefficient & P value \\
\hline Knowledge & 1.37 & .29 & 0.134 & 0.111 \\
\hline
\end{tabular}

In order to opt between parametric and non-parametric test, normality was carried out. Since, normality test shows $p=<0.05$, which signifies that the collected data of this study were not normally distributed. So Mann Whitney test and Kruskal Wallis tests (non-parametric) were performed to examine relationship between selected demographic variables and knowledge and practice on ethico legal aspect. Mann Whitney test was performed to see differences of knowledge and practice according to different educational background. Test showed that knowledge and practice was not differed as per different educational level (table 3). Likewise according to table 4, years of experiences of nurses did not affect their knowledge and practice of nurses pertaining to ethico legal aspects. To a certain extent, it was shocking that level of education and years of experience did not affect knowledge and practice related to ethico legal aspects of nursing. As shown in table 5, Spearman- Correlation coefficient test was performed to examine relationship between ethico-legal knowledge and practice of participants. Findings of the study indicated that there was positive relationship between knowledge and practice. However it was not statistically significant $(r=0.134 \& p=0.111)$.

\section{DISCUSSION}

Findings disclosed that majority of participants had -bachelor and above education 97(68.3\%), as per years of experiences majority had less than 5 year's experiences $88(62 \%)$. Regarding knowledge of legal ethical issues findings of this study was reverse or higher than the findings of Shrestha et al, ${ }^{6}$ since in both study there was adequate level of practice regarding of ethics and law. However, finding of present study had higher score regarding nurse's knowledge on ethics and law where nurses had no satisfactory knowledge on ethics and law. ${ }^{6}$ Whereas, findings of Kaur et al, ${ }^{1}$ shows that there was no significant relationship between nurse's knowledge and duration of clinical experience which is similar to the findings of present study. However, regarding level of education and knowledge this study is reversed than Kaur et al where there was a significant association between level of knowledge and their professional qualification.

Similarly, finding of present study was differentiated to the result of another study; which reveals that level of education and years of clinical experience had significant relationship with encounter of ethico legal aspect of nursing. ${ }^{8}$ Finding of present study is higher than the findings of a study which was conducted in the hospitals of Kashan University of Medical Sciences among 200 nurses, which reveal that overall, knowledge of ethical and legal issues in elderly care was not satisfactory. ${ }^{9}$ A finding of present study is little bit lower than the finding of a study carried out in Spain. In this study all participants demonstrated that they had sufficient knowledge on ethical aspects of nursing. ${ }^{10}$ Where as in present study there was only average level of knowledge regarding ethical legal issues.

Finding of present study is more or less similar than a study conducted in psychiatric setting; where $90 \%$ of the nurses' had average level of awareness on ethical aspects of nursing profession. Statistically, no significant relationship was seen between total clinical experience and nurses' knowledge regarding ethical aspect. However, regarding professional qualification this study is reverse than that because there was significant relationship between level of professional education and knowledge on ethical legal issues. ${ }^{3}$

Regarding nurses exposure with ethical issues this study shows very nominal exposure as reported by nurses which was very lower than findings of a study conducted in Malaysia where $95.2 \%$ nurse administrators felt ethico legal issues at some time of their clinical experience. In aggregation, 47.2\% nurses perceived ethical issues daily to weekly. ${ }^{11}$ In order to see relationship between knowledge and practice spearman correlation coefficient test was applied. It is seen that there is positive correlation between them however, statistically it is not significant $(r=0.134 \& p=0.111)$. Similarly, finding of this study was also more or less similar to findings of Hepsibah Sharmil, where nurses had moderate level of knowledge. ${ }^{12}$

This study was a single centered study along with small 
sample size these are the main confines of the present study. However, study had several possible inferences for nursing profession. For example, it was able to make aware the nurses, it might be able provide foundation for other large scale study and it compels Nursing Department of the concerned hospital to augment additional educational package into regular continue nursing education.

\section{CONCLUSIONS}

Nurses require adequate knowledge towards legal sides of the nurses, as it increases the excellence care and also provide legal safeguard to the nurses. This study reveals that Nurses had average knowledge and practice on ethico legal aspects. There is positive relationship between knowledge and practice however, it is not statistically significant. Findings of present study illustrate that overall nurses knowledge was moderate, so that nurses require enlightening of ethico legal awareness through continue nursing education. However, larger scale study and comparative study among nurses of different hospitals have to be conducted in order to draw conclusion and generalization.

\section{ACKNOWLEDGEMENTS}

Firstly, researchers' heartfelt thank goes to IRC (Institutional Review Committee) of Shahid Gangalal National Heart Centre for providing consent to carry out this study. In the same way, researchers' sincere gratitude to all the nurse participants of Shahid Gangalal National Heart Centre for contributing their valuable time cooperatively. Last but not the least, researchers would like to pay homage to Mr. Bibhav Adhikari for providing guidance in statistical analysis.

\section{REFERENCES}

1. Kaur H, Sodhi JK, Sharma K. A Study to Assess the Knowledge Regarding Legal Responsibilities in Nursing. Int J Health Sci. 2014; 2(1): 50-53.

2. Kelsen H. Pure Theory of Law. 1960.

3. Kumar R, Mehta S, Kalra R. Knowledge of staff nurses regarding legal and ethical responsibilities in the field of psychiatric nursing. Nursing and Midwifery Research. 2011;7(1):1-1.[Full Text]

4. Chaloner C. An introduction to ethics in nursing. Nurs Stand. 2007;21(32):42-6. [PubMed]

5. Cochran WG. Sampling technique ( $3^{\text {rd }}$ ed). New York. John Willey \& Son.1977.
6. Shrestha S, Jose P. Knowledge and practice of nursing ethics and laws. Journal of Universal College of Medical Sciences. 2014;2(3):30-3.[Full Text]

7. Assefa T, Gedif T, Alemayehu B. Evaluation of patients' knowledge on warfarin therapy among outpatients receiving warfarin at tikur anbessa specialized hospital, Addis Ababa, Ethiopia. Ethiop Pharm J. 2014;30:133-8. [Full Text]

8. Furlong E. Right or wrong: legal and ethical issues and decision making. Decision-making in nursing: thoughtful approaches for practice. Sudbury, MA: Jones and Bartlett Publishers. 2008:29-46.[Full Text]

9. Hajbaghery MA, Safa A, Aminolroayaee-Yamini E. Nurses' knowledge of ethical and legal issues in elderly care. Medical Ethics Journal. 2015;9(31):169-91.[Full Text]

10. Losa Iglesias ME, Becerro de Bengoa Vallejo R. Nurse attitudes in relation to health care ethics and legal regulations for nursing. Acta Bioethica. 2014;20(2).[Full Text]

11. binti Musa M, Harun-Or-Rashid M, Sakamoto J. Nurse managers' experience with ethical issues in six government hospitals in Malaysia: A cross-sectional study. BMC Med Ethics. 2011;12(1):23.[Full Text]

12. Sharmil SH. Awareness of community health nurses on legal aspects of kealth care. Int J Public Health Res. 2011:199-218. [Full Text] 